\title{
Experimental Research on Bearing Capacity of Cold-formed Steel Double-Shaft Built-up Long Columns
}

\author{
Wang Qun ${ }^{1, a *}$, Yan Xin'e ${ }^{1, b}$, Zhang Qian ${ }^{1, c}$ \\ ${ }^{1}$ Xi'an Eurasia University, Shanxi, Xi'an 710065, China \\ a wangqun.only@163.com, b531832488@qq.com
}

Keywords: Cold-formed steel, built-up sections, long columns, experimental research, effective width

\begin{abstract}
Cold-formed steel built-up columns are the main components in cold-formed steel framing residential buildings, however, there are short of reliable experimental and theoretical study on cold-formed steel built-up columns in China. Technical code of cold-formed thin-wall steel structures (GB50018-2002) in China only consists of the axial compression test of single component. In order to investigate the mechanical behavior of built-up members, two groups of cold-formed steel double-shaft built-up long columns were tested under axial compression load. The load capacity and the failure characteristic of the specimens were analyzed in this paper. The wall thickness of specimens are all $1.6 \mathrm{~mm}$, the length of all the columns are $3 \mathrm{~m}$. The results of experimental research show that using effective width method of Chinese code GB 50018-2002 and AISI to calculate the load capacity of cold-formed steel built-up long column is safe. The failure modes of all specimens are flexural bucking.
\end{abstract}

\section{Introduction}

In the recent few years, the lightweight construction has been developed so fast for its excellence on overall efficiency, and cold-formed thin-walled section steel residential system has already processed from low class into diverse classes. As for the cold-formed thin-walled section steel residential system, the compound section upright column is its major supporting member, however, the relevant experimental investigation on its related behavior and bearing capacity is very insufficient at home and abroad, for lacking of enough test, no reliable quantitative description can be formed. The current standard in our country $<$ The technical code cold-formed thin-walled section steel structure $>$ GB50018 ${ }^{[2]}$ majorly focuses on the calculation of the single section C shaped and single section $U$ shaped pulldown members. So, in order to expand the applied range of the cold-formed thin-walled section steel at home, to understand the structural behavior of the compound member in cold-formed thin-walled section steel, to examine whether the rules of current standard GB50018 is proper or not, it is necessary to make a further research. The author made the experimental investigation mainly on the puuldown bearing capacity of two groups battened compound section in cold-formed thin-walled section steel, made analysis and comparison on the structural behavior of different forms compound section.

\section{Test pieces}

The thickness of test piece is $\mathrm{t}=1.6 \mathrm{~mm}$, length is $3 \mathrm{~m}$. The specification of the $\mathrm{C}$ shaped cold-formed thin-walled section steel is $\mathrm{C} 140 \times 41 \times 13 \times 1.6 \mathrm{~mm}$, the specification of the $U$ shaped cold-formed thin-walled section steel is $\mathrm{U} 140 \times 32 \times 1.6 \mathrm{~mm}$. According to the different compound modes, test pieces were divided into 2 groups. Long column ones were designed as the form of 
section shown in Fig.1(a), group 1 is the I-section which made-up by two 'back to back' $\mathrm{C}$ shaped cold-formed thin-walled section steel(LC-1), group 2 is the amplexus closed-end in compound section which made-up by one $\mathrm{C}$ shaped and $\mathrm{U}$ shaped cold-formed thin-walled section steel(LC-2). The test pieces were connected by the ST4.8 self-drilling tapping screws, as is shown in Fig. 1(b), the spacing between screws is $300 \mathrm{~mm}$, for enhance the end of the test pieces, more screws were added under the bottom of the pieces $100 \mathrm{~mm}$. The end of the test piece were connected with $U$ shaped steel as a support, to model the real applied state in the practical project. The bent edge radius of the section is shown in Fig.1(a), r=3t. Before test, all the end of test pieces were given sanding treatment, made sure the end face is vertical with axis and completely contacted in all the section of the support end plate. By the result from the material behavior test, the material behavior index took the elastic ratio $\mathrm{E} \approx 2.23 \times 10^{5} \mathrm{MPa}$, the yield strength $\mathrm{f}_{\mathrm{y}} \approx 334.04 \mathrm{MPa}$.

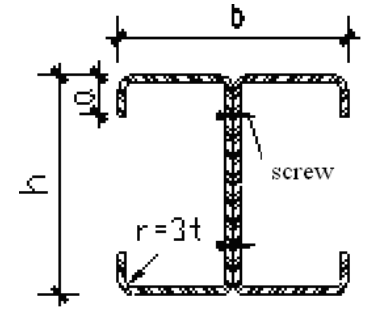

(a) Cross-section of test piece

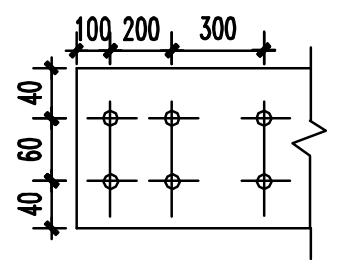

(b) Screw separation

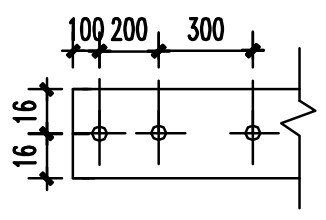

Fig. 1 Long column specimen
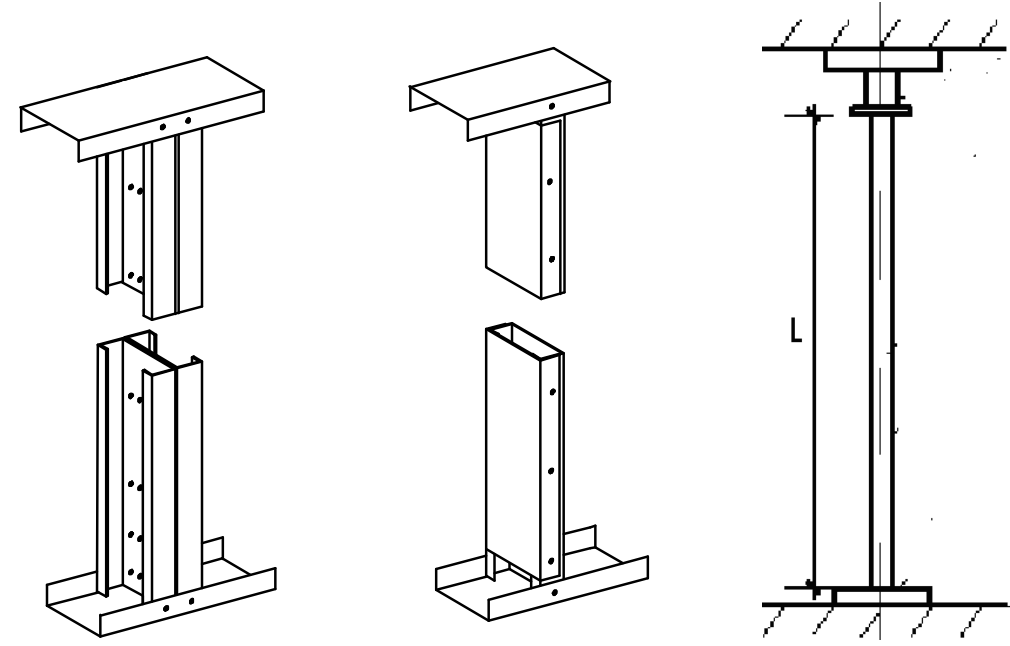

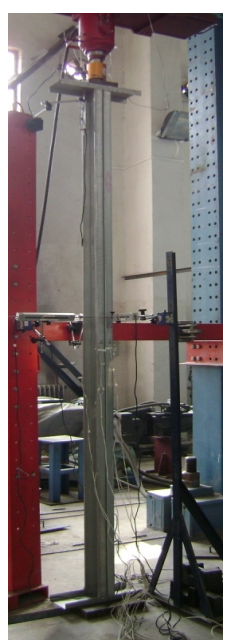

Fig.2 Charger

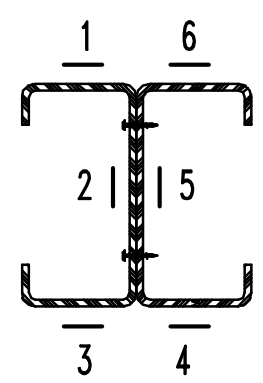

(a) Arrangement plan of foil gage
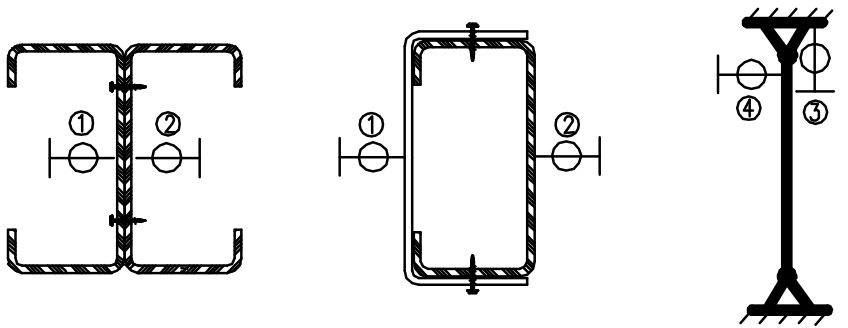

(b) Arrangement plan of displacement

Fig. 3 Arrangement of measuring point 


\section{Test devices and the layout of the survey points}

The test used hydraoulic jack to load, as is shown in Fig.2. The layout of the survey points on each test pieces is shown in Fig.3, at web plate of the section in the midspan in test pieces and flange girth, strain-gages were added symmetrically, in testing the pieces on the relation between the load and strain; separately layed out displacement recorder D1 and D2 at web plate of the section in the midspan in test pieces, to measure the deformation of the test pieces in all levels load, layed out vertical displacement recorder D3 and horizontal displacement recorder D4 on the top of the test pieces, to measure the deformation of axial compression and top horizontal displacement on the test pieces in all levels load. The data was collected and recorded by the TDS-602 Data collector.

\section{The process of test and the features of damage}

When the test is being started, we put the planished and gang mounted test pieces on the platform of the test machine, at first, geometric alignment was made on the test, then $1 \mathrm{KN}$ prepressing load was applied in, and examined the physical alignment state by reading the number on strain-gage, if there was no errors after the examination, then the load could be applied formally. During the

process of this test, graded load was controlled manually, each graded load would last 2-3min, collected and recorded the data by dotting; when the load reached its limit, generally the obvious trace could be found from the displacement recorder and the variation of the strain reader, specifically, when increased the horizontal displacements and strains drastically. Apparent entire flexion happened on the test piece immediately, at this moment, load could not be added, the piece would entirely destabilize presently. Observed and recorded the phenomenon of the test from time to time. Each phenomenon of the test and damage features could be summarized as followings:

(1) The final damaging model of the test piece is same as predicted before, entire flexural destabilized damages all happened. As the Fig. 4(a). But for the degree of geometrical alignment is different, The development of the pieces which would have flexural deformation during the loading process could be divided into 2 types: In first type, the alignment was not perfect, so when started loading, the piece would have flexural deformation during the effect of the eccentricity pressure, then in the end, destabilization happened at the peak point; however, the alignment in second type is kindly perfect, the section of the test piece beard the even pressure, the flexural deformation was not clear before the piece damaged, the whole piece basically kept being straight in the process of the test, it would not have flexural deformation and broke suddenly until the critical load being reached, its damaging model is close to the perfect compression bar.

(2) Because the thickness of the test section was smaller $(t=1.6 \mathrm{~mm})$, the width of the plate is was bigger, the crucial load of elastic partial flexion on plate is not big, most pieces would have the phenomenon of elastic partial flexion on plate before the entire flexion happened. As is shown in Fig. 4(b), the semiwave length of the flexion in the partial flexion was approximately equal to the web plate height on the test piece.

(3) After the unload, for the length of the test piece was bigger, most of the partial deformation could be recovered, this indicated the partial flexion basically happens at the phase of elastic or elasto-plasticity.

(4) Before all the test pieces turned into damage, there was no bearing damage on the end of the test pieces, only few of them dropped self-tapping screws, the main reason for this is the errors in 
consolidation, it means the connection of self-tapping is reliable.

(5) During the process, distorted flexion happened in the curling of the opening section pieces in the first group member, shown in Fig. 4(c), opened and closed situation occurred in the section, the critical stress of distorted flexion was less than partial flexion.

The phenomenon of the test and damaging model basically match with the result in the experimental investigation on the reference ${ }^{[3],[4]}$.

\section{The main results in the test}

According to Fig.3, after layed out the displacement recorder, all pieces' typical curved drawing showing the relation between the load which was collected and recorded and the displacement on Fig.5; typical curved drawing showing the relation between the load which was collected also recorded on the strain-gage and the strain relation on Fig.6, the limit load $P_{t}$ in the test when destabilized damage happened to all pieces shown on the form 1.

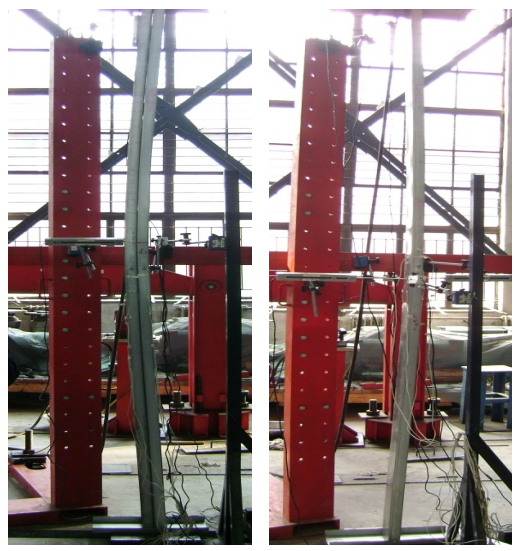

(a) bend buckling

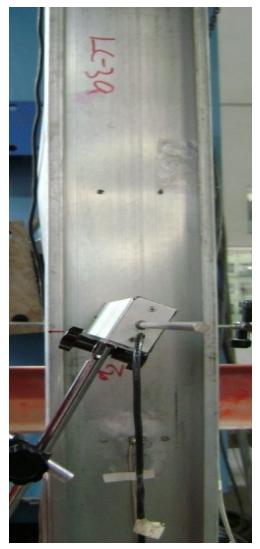

(b) part buckling

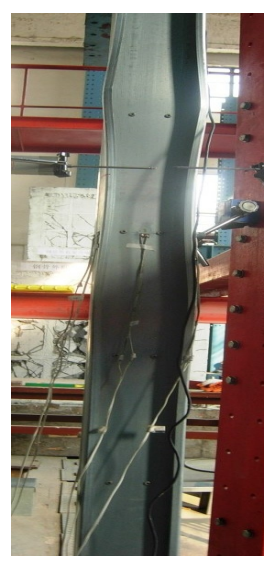

(c) distortiong bucking

Fig. 4 Damage pattern

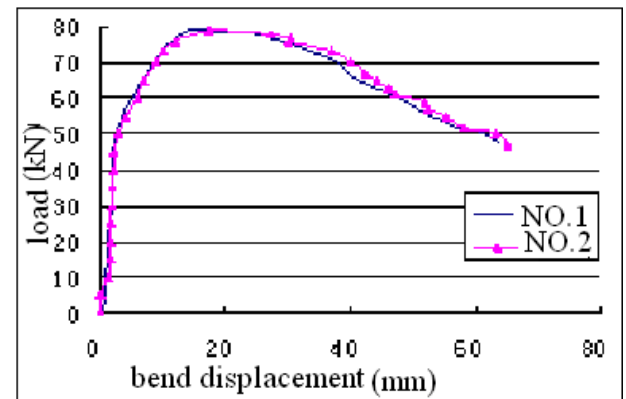

(a) Curver of LC-1 load-bend displacement

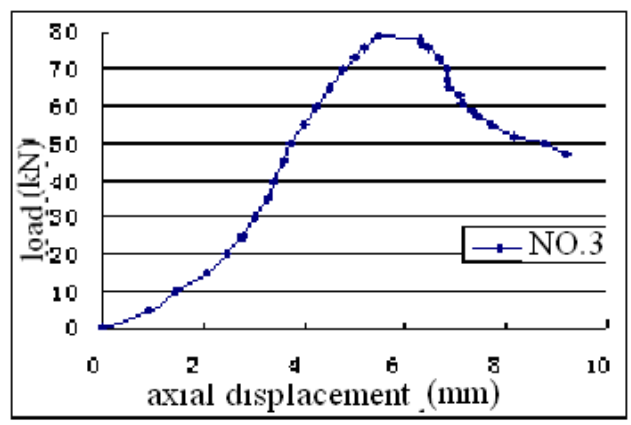

(c) Curver of LC-1 load-axial displacement

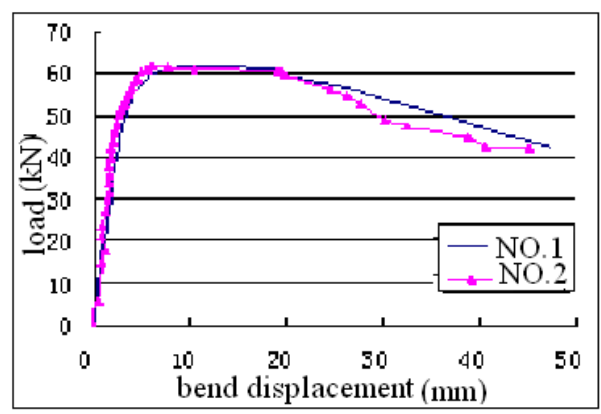

(b) Curver of LC-2 load-bend displacement

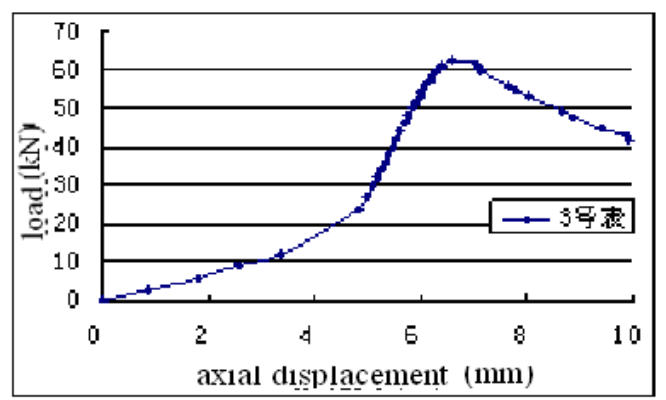

(d) Curver of LC-2 load-axial displacement

Fig. 5 Typical curver of load-displacement 


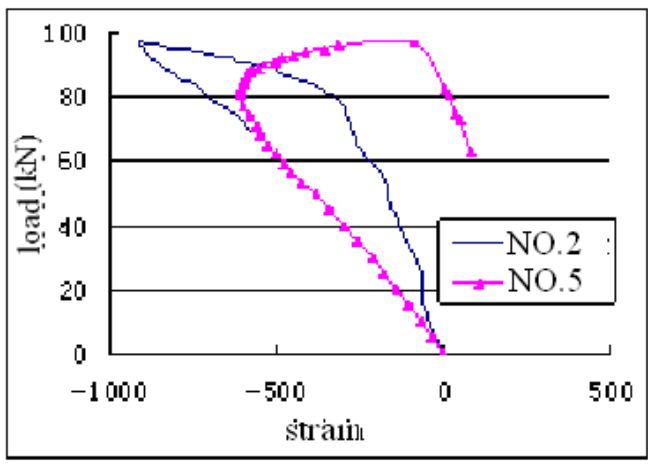

(a) Curver of LC-1 load-strain

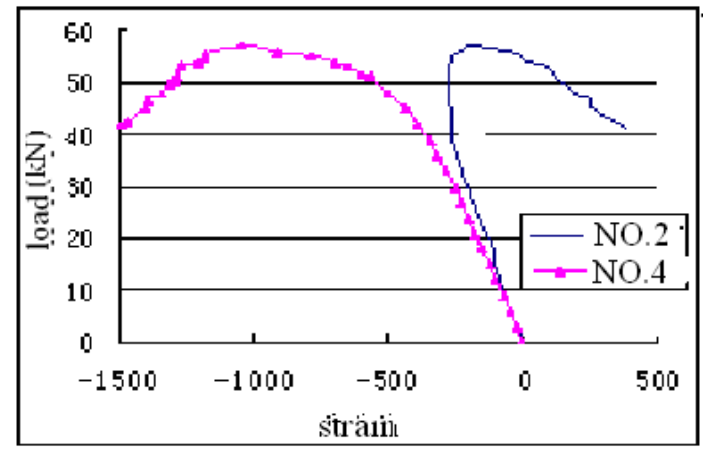

(b) Curver of LC-2 load-strain

Fig. 6 Typical curver of load-strain

\section{The comparison of the test and the calculation of bearing capacity}

According to the rule of GB50018 ${ }^{[2]}$ in our country, the stable bearing capacity of compression on axial take $N=j A_{e} f$ in to calculation. The theoretical damaging model of biaxialsymmetrical sections in this article are all the flexural destabilization rounded the weak axis.

Our national code GB50018 rules that take the following formulas into the calculation on efficient width:

when $b / t £ 18 a r: b_{e}=b$

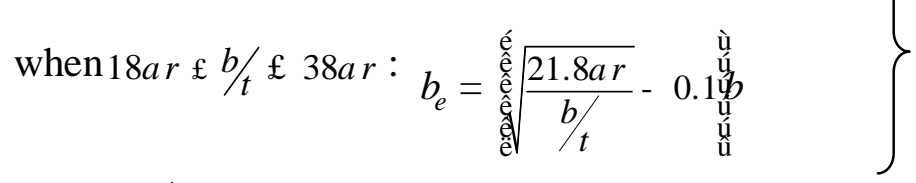

when $b / t^{3} 38 a r: b_{e}=\frac{25 a r}{(b / t)} b$

In the formulas: $r=\sqrt{235 k_{1} k / s_{1}}, \mathrm{k}$ is the stable coefficient of the plate in compression, $\mathrm{k}_{1}$ is the restraint coefficient of the plate, $s_{1}=j f_{y}$. According to formula (1), web plate would be calculated as the stiffening plate, flange girth would be calculated as the partial stiffening plate, curling would be calculated as unstiffening plate, the coefficient of flexion on plate $\mathrm{k}=4.0$, relevant restraint impact had been considered, The calculation of the restraint coefficient $\mathrm{k}_{1}$ plate groups and the efficient section area $A_{e}$ test pieces is on the reference ${ }^{[5]}$. The rest meaning of symbols is on the reference ${ }^{[2]}$. Something need to be pointed out, the calculation method of efficient width in all kinds of combining forms is approximate: treat it as separate section to calculate its efficient width individually, then make nestification on it.

By the slenderness ratio $\lambda$ of the test piece, stable coefficient $j$ can be found in China code ${ }^{[2]}$, to replace the designing strength $\mathrm{f}$ of the steel materials into the yield strength $\mathrm{f}_{\mathrm{y}} \approx 334.04 \mathrm{MP}$ of the materials in test pieces, namely, the limit bearing capacity $\mathrm{N}_{\mathrm{u}}$ of relevant impact in plate group of test pieces can be acquired.

No need to consider the relevant impact when calculating the efficient width in the US standard 
$\mathrm{AISI}^{[6]}$, as the following formula:

when $x^{3}$ 0.673: $b_{e}=b$

when $x<0.673: b_{e}=r b$

and

$$
\begin{aligned}
r & =(1-0.22 / x) / x \\
x & =\sqrt{\frac{f}{s_{c r}}}=\frac{1.052(b / t)}{\sqrt{k}} \sqrt{\frac{f}{E}}
\end{aligned}
$$

The formula of stable bearing capacity in pulldown member is:

$$
N_{u}=A_{e} F_{n}
$$

when $l_{c} £ 1.5, F_{n}=\left(0.658^{l_{c}^{2}}\right) f_{y}$

when $l_{c}>1.5, F_{n}=\frac{\stackrel{\gtrless}{e} 0.877}{l_{c}^{2}} \frac{\ddot{Q}}{\dot{\bar{\dagger}}} f_{y}$

and : in $l_{c}=\sqrt{f_{y} / F_{e}}, \mathrm{~F}_{\mathrm{e}}$ - The minimum value of elastic flexion, torsion, flexion stress same thing, to replace the $\mathrm{f}$ in (2) with $\mathrm{f}_{\mathrm{y}}$ when calculation is being made, to see the form 1 in the calculation method of on the compound section and the acquired efficient section area and the limit bearing capacity from US codes AISI ${ }^{[2]}$ and reference ${ }^{[1]}$.

In order to make comparison, $\mathrm{C}$ shaped and $\mathrm{U}$ shaped section pieces was calculated by the standards from China and US, the following is the acquired limit bearing capacity.

For the single C shaped: $N_{u 1}=18.5 \mathrm{kN} \quad N_{u 1}^{\varnothing}=19.2 \mathrm{kN}$

For the single U shaped: $N_{u 2}=11.3 K N \quad N_{u 2}^{\phi}=12.5 K N$

And: $N_{u 1}, N_{u 2}$ is the standard calculation value in China; $N_{u 1}^{\varnothing}, N_{u 2}^{\varnothing}$ is the standard calculation value in US.

So, it can be concluded, the limit bearing capacity of battened compound section pulldown members is obvious greater than the sum of linear nestification in the single section member bearing capacity.

It can be known from the comparison on data in form 1,the theoretical bearing capacity influenced by China code GB50018 is less than the limit bearing capacity acquired from the US code AISI. However the test value $\mathrm{P}_{\mathrm{t}}$ acquired is greater than the corresponding limit bearing capacity $\mathrm{N}_{\mathrm{u} 3}, \mathrm{~N}_{\mathrm{u} 4}$,also $\mathrm{P}_{\mathrm{t}} / \mathrm{N}_{\mathrm{u} 3} \approx 1.16-1.44, \mathrm{P}_{\mathrm{t}} / \mathrm{N}_{\mathrm{u} 4} \approx 1.14-1.42$.

\section{Conclusions}

(1)The final damaged form of all test pieces are even the flexural deformation damages, before the entire member broke down, the general section plate could also have partial flexion and flexural deformation. It is all feasible to calculate the bearing capacity of the compound section in axial compression member by China current standard < The technical code cold-formed thin-walled 
section steel structure > GB50018 and US standard AISI, but the bearing capacity acquired from the relevant impact on section plate by the China code GB50018 is smaller. Compared with the bearing capacity which is calculated from the efficient area and to index the stable coefficient on code with the features of gross section, the test result is greater than the theoretical calculation values, the theoretical calculation values on US and China standard is on the safe side.

(2) The bearing capacity on pulldown member of the compound cold-formed thin-walled section steel is far outweigh than the sum of linear nestification on a single section member. Several single section members' pulldown bearing capacity can be taken into consideration when it is necessary in designing.

(3)Compound section members were connected by the self-tapping screws which are in $300 \mathrm{~mm}$ spacing, this can satisfy several members' collaborative work, very reasonable.

\section{Reference:}

[1] Wei Wen-Yu. Cold-Formed Steel Design[M]. New York, NY: Wiley \& Sons, Inc,2000.

[2] GB50018-2002, < The technical code cold-formed thin-walled section steel structure > [S]

[3] T.A.Stone, R.A.LaBoube. Behavior of cold- formed steel built-up I-sections[J]. Thin-Walled Structures,2005,43: 1805-1817.

[4] Zhou tian hua, He bao kang, Zhou xu hong, etc. The experimental investigation on the structural behavior on pulldown long column high-strength old-formed thin-walled section steel [J] Construction science and engineering newspaper, 2005,22(4): 65-71

[5] Zhou tian hua, He bao kang, Zhou xu hong, etc. The experimental investigation on the structural behavior on pulldown short column high-strength old-formed thin-walled section steel [J] Construction science and engineering newspaper, 2005,22(3): 36-44

[6] AISI /COS/NASPEC, North American Specification for the Design of Cold-formed Steel Structural Members[S],2001. 